Egyptian

Orthodontic Journal

\title{
RATINGS OF PROFILE ATTRACTIVENESS AFTER FUNCTIONAL MANDIBULAR ADVANCEMENT
}

\author{
Nabeel Abou Shamaa ${ }^{1}$, Mohamed Adel Nadim²
}

\section{ABSTRACT:}

Considerations involving orthodontic treatment and facial esthetics have directed the investigation of the optimal treatment, especially in the correction of Class II, division 1 malocclusions, both esthetically and functionally.

The aim of this study is to determine whether the use of a Twin force bite corrector in combination with Edgewise mechanics yields a more esthetic facial profile than Edgewise treatment alone.

Methods: The present retrospective study compared matched two groups of adolescent patients, (total $n=20)$ The first, treated with functional orthopedic therapy using a TFBC in combination with preangulated Edgewise appliances, $(n=10)$. The second, matched group ( $n=10)$ was treated using standard Edgewise mechanics alone. A panel of ten orthodontic graduate evaluators investigated silhouettes of lateral photographs of perceived post treatment facial esthetics of Egyptian adolescents with Class II, division 1 malocclusions treated by one of the two methods. They scored each silhouette's attractiveness on a 100\% visual analogue scale (modified VAS). Independent samples $t$ test at 0.05 level of significance was used to compare the VAS scores. Results: the evaluators showed wide range of agreement among the two treated groups in selecting the most attractive profiles. The evaluation of pre/post treatment for each group and randomized post treatment

1- Assistant Professor, Orthodontic Department, Suez Canal University.

2- Lecturer, Orthodontic Department, Suez Canal University 
Egyptian

Orthodontic Journal

of both goups for facial attractiveness showed insignificant difference statisticaly. Conclusion: TFBC treatment in combination with Edgewise mechanics has measurable benefits.

Key words: Facial profile, Twin force bite corrector, functional orthopedic therapy

\section{INTRODUCTION}

Facial esthetics is an important personal and social concern. Attractive facial appearances are judged to possess more socially desirable personality traits (e.g., Shaw 1981) ${ }^{1}$, and favorable facial esthetics are related to psychosocial well- being by children, young adults, and parents (Shaw et al., 1985'; Birkeland et al. $2000^{3}$ ). In addition, parents believe their child would become better liked, more successful, and overall more attractive because of esthetic improvements coincident with orthodontic treatment (Shaw et al. 1979) ${ }^{4}$. Hence, facial esthetics is an important concern within the specialty of orthodontics.

The effects of orthodontic therapy on facial esthetics has been a long-term concern within the orthodontic community (Spyropoulos and Halazonetis $2001)^{5}$, but these effects also are a concern of orthodontic patients and their parents (Shaw 1981'; Shaw et al. 1985' ; Birkeland et al. 2000 Shaw et al. $1979^{4}$; Vig et al. $1999^{6}$;). Indeed, orthodontic treatment is sought for one of three reasons, namely the presence of facial disharmony, the malalignment of teeth, or some combination of these two problems (Vig et al. 1999) ${ }^{6}$. Therefore, maximizing facial esthetics is a necessary consideration during orthodontic treatment planning.

There are several treatments currently used in the correction of Class II malocclusions, including a variety of extraoral traction devices (e.g., facebows and headgears), dentoalveolar distalizing appliances (e.g., Pendulum/Pendex appliance and the Distal Jet), the extraction of teeth, orthognathic surgery, and functional orthopedic appliances (e.g., the Activator, the Bionator, the Fränkel appliance, the Herbst appliance, the twin block appliance (Graber et al. 2005) ${ }^{7}$. However the TFBC, the most recent fixed functional appliance to become commercially available, has never been evaluated for its esthetic effects on the facial profile. 
Egyptian

Orthodontic Journal

\section{Subjects:}

The total sample consists of 20 subjects (10 patients for each group) chosen from patients treated in the Department of Orthodontics, Suez Canal University, Ismaillia, and private clinic with inclusion criteria of: (1) Class II division 1 malocclusion due to a skeletal discrepancy caused by mandibular retrognathism, (2) Fully erupted permanent dentition (often excluding second and third molars). (3) With an age range of 12-15 years

The sample is divided into two groups; Group 1: the twin force bite corrector (TFBC) group where treatment consisted of orthopedic functional therapy using a TFBC in combination with standard Edgewise appliances and Group 2: the Edgewise group where the subjects were treated by edgewise appliance. For the later group, the age at treatment onset was matched when compared to subjects of the first group; and treatment consisting of extractions of either upper first premolars and lower second premolars, upper first premolars only, or all first premolars, and standard Edgewise mechanics. Pre- and post-treatment lateral cephalograms and lateral photographic images of the soft-tissue outline were taken for all subjects. Subjects in the two treatment groups were matched, on a one-to-one basis, for cephalometric variables (SNA, SNB, ANB, FMA) to ensure comparability in the nature and severity of the malocclusions (table 1).

Table 1: Matching of cephalometric variables at the pretreatment examination.

\begin{tabular}{|l|c|c|c|c|c|c|c|c|c|}
\hline \multirow{2}{*}{} & \multicolumn{2}{|c|}{ SNA Angle } & \multicolumn{2}{c|}{ SNB Angle } & \multicolumn{2}{c|}{ ANB Angle } & \multicolumn{2}{|c|}{ Mp/ SN } & \multirow{2}{*}{ N } \\
\cline { 2 - 9 } & Mean & S D & Mean & S D & Mean & S D & Mean & S D & \\
\hline TFBA & 81.1 & 0.876 & 75.0 & 1.414 & 6.1 & 2.079 & 35.8 & 3.584 & 10 \\
\hline Edgewise & 80.5 & 1.354 & 75.6 & 1.265 & 5.1 & 1.853 & 36 & 1.699 & 10 \\
\hline
\end{tabular}

\section{Esthetic Evaluation}

It was decided that silhouettes would provide the best presentation of the profiles for the present study. With the unclear influence of sex on panel ratings, both male and female observers (consisting of 10 graduate orthodontic students), were used for this study. 
Egyptian

Orthodontic Journal

\section{Silhouette Evaluation:}

Profile silhouettes were chosen for rating the profiles, rather than lateral photographs, to avoid subjective considerations and eliminate aspects that may influence the observers, such as hair color and hair style, skin complexion, make- up, or age (Shelly et al. $2000^{8}$; Mergen et al. 2004 ${ }^{9}$ ). In turn, the silhouettes eliminated any distracting extrinsic or intrinsic variables that could influence the observer's esthetic rating, allowing him or her to focus on the outline of the facial profile. Although previously anticipated, (Spyropoulos and Halazonetis 2001) ${ }^{5}$ verified the influence that inherent factors that occur in photographs possess in biasing ratings of profile esthetics. The evaluated lateral photographs that had been altered but with identical profile outlines. Photographs were documented not to be good determinants of profile esthetics, which supports the use of silhouettes in profile evaluations to eliminate influences from other facial features.

The solid black silhouette images (Appendix) were generated from pre-treatment and post-treatment digitized lateral photographs using Adobe Photoshop 5.5 (Adobe Systems Incorporated, San Jose, CA) at a resolution of 72 dot per inch $\{\mathrm{dpi}\}$ both for vertical \& horizontal. For this study each digital image was rotated, if necessary, in Adobe Photoshop 5.5 to position the Frankfort plane (Fig.1 a\&b) horizontally.
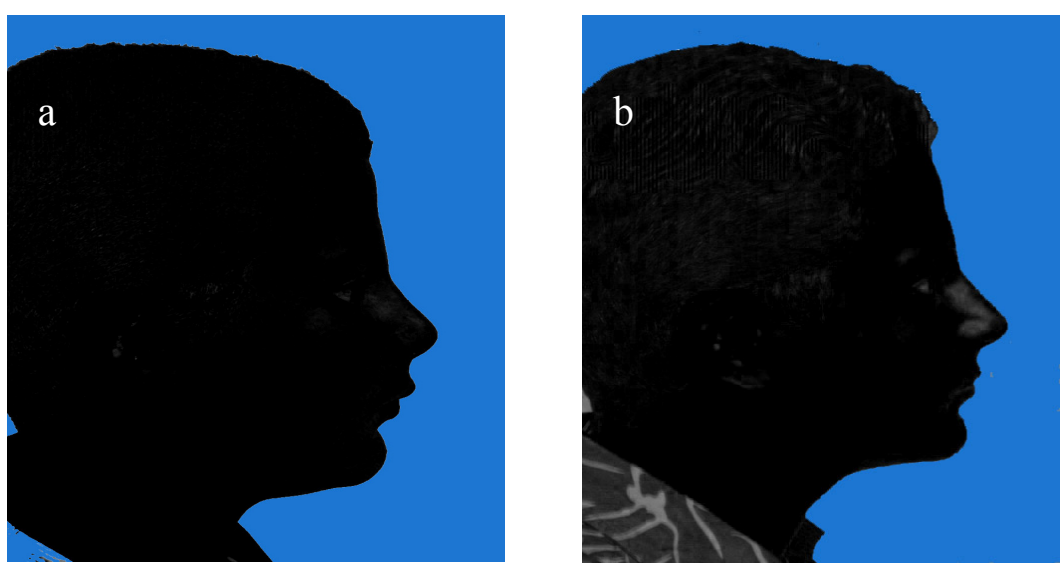

Figure 1: Edgewise group a, Before treatment. b. After treatment 
Egyptian

Orthodontic Journal

\section{Method of rating:}

Ten graduate orthodontic students, orthodontic department, Faculty of dentistry, Suez Canal University rated the level of profile attractiveness pre and post orthodontic treatment. The observers were not informed that they were evaluating two different treatment methods.

The Visual Analogue Scale

The Visual Analogue Scale (VAS) assessment rating method was chosen for this study given its reproducible and accurate assessment of panel ratings. It was also chosen for its unproblematic and rapid measurability, as well as the lack of excessive explanation required for its use (Howells and Shaw 1985 ${ }^{10}$; Proffit et al. $1992^{11}$; Bowman and Johnston $2000^{12}$; O’Neill et al. $2000^{13}$ ).

In this study we used a modified scale by incorporating a table with percentage. The observers were asked to evaluate the randomized pretreatment and post-treatment profile silhouettes of group 1 and group 2 using an unmarked modified VAS (in a form of a table) and anchored by the descriptors $0 \%$ (very unattractive) and $100 \%$ (very attractive) at right side (Figure 2).

Fig.2: Example of the modified VAS used in part 1of the esthetic evaluation

\begin{tabular}{|c|c|c|c|c|c|c|c|c|c|c|}
\hline $\begin{array}{c}0 \% \\
\text { Non } \\
\text { Attractive }\end{array}$ & $10 \%$ & $20 \%$ & $30 \%$ & $40 \%$ & $50 \%$ & $60 \%$ & $70 \%$ & $80 \%$ & $90 \%$ & $\begin{array}{c}100 \% \\
\text { Very } \\
\text { Attractive }\end{array}$ \\
\hline & & & & & & & & & & \\
\hline
\end{tabular}

Observers marked all VAS scores on a provided document after detailed instructions on properly marking the VAS were provided in the tutorial. For this evaluation the randomized silhouettes were individually presented in the screen. The rater first marked which profile he preferred, and then the rater used the VAS scale (in percent) to score how much he preferred one silhouette over the other.

Next, both post-treatment silhouettes of both groups were shown side-by-side on a single view, also in random order. Then observers were asked to evaluate the preferred profile esthetics of the profile presented on 
the right or on the left by checking a box marked L for left (group 1) or R for right (group 2) on the provided handout. Then, observers marked the intensity of their preference as described above (fig.3).

Fig. 3: Example of the modified VAS used in part 2 of the esthetic evaluation

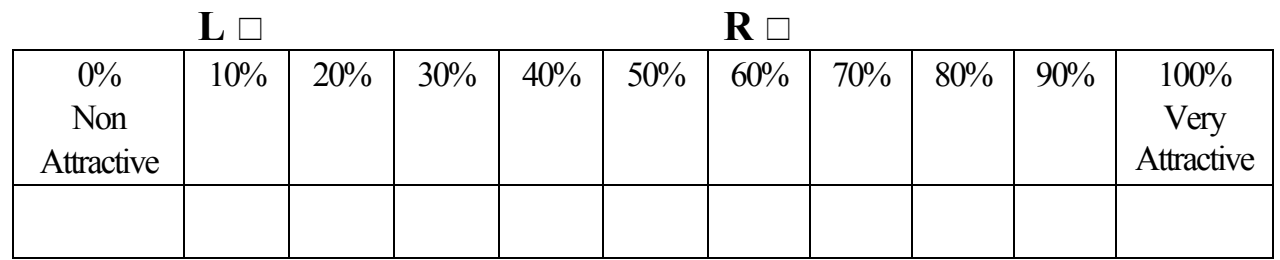

L: Group 1

R: Group 2

\section{Evaluation Format}

The silhouettes were presented in the form of a Microsoft (Microsoft, Redmond, WA) Power Point presentation, in the department teaching hall to the 10 observers. A slide-show tutorial was provided with (1) directions, (2) practice examples, and (3) detailed instructions on properly marking a VAS were given to familiarize raters with the format of the evaluation. Observers then marked the intensity of their preference as described on the provided handout.

\section{Statistical Methods}

Data were collected and conventional descriptive statistics were calculated for each treatment group. The conventional level of 0.05 was used throughout, and statistical independent samples $t$ test was used to examine the effects and the interactions among the two groups of treatment.

\section{RESULTS}

Descriptive statistics was used to compare the total marks of the 10 raters for each face and thus evaluate the influence of the anteroposterior mandibular position-in a side view-in determining facial attractiveness.

\section{Observers' Perceptions of Pretreatment and Posttreatment Profiles}

Table 2 allows an analysis of the mean and confidence interval (at 95\% attractiveness) that the different profiles exert on all raters, according to facial attractiveness for both groups. Both groups showed no significance at $5 \%$ level of confidence. 
Egyptian

Orthodontic Journal

Table 2: Results of $\mathrm{t}$ - test evaluating the signed VAS changes treatment in evaluation of the Silhouettes at the Pretreatment and Posttreatment examination for both groups:

\begin{tabular}{|c|c|c|c|c|c|c|c|c|c|}
\hline \multirow{2}{*}{ Group } & \multirow{2}{*}{$\mathrm{N}$} & \multicolumn{7}{|c|}{$95 \%$ Confidence Interval of the Difference } \\
\cline { 3 - 10 } & Mean & $\begin{array}{c}\text { Std. } \\
\text { Deviation }\end{array}$ & $\begin{array}{c}\text { Std. Error } \\
\text { Mean }\end{array}$ & Upper & Lower & df & $\mathrm{t}$ & Sig. (2-tailed) \\
\hline GP 1 & 10 & 63.30 & 11.835 & 3.74255 & 71.7662 & 54.8338 & 9 & 16.914 & .000 \\
\hline GP 2 & 10 & 55.60 & 16.270 & 5.14501 & 67.2388 & 43.9612 & 9 & 10.807 & .000 \\
\hline
\end{tabular}

Group 1 (TFBC) Group 2 (Edgewise)

\section{Observers' Perceptions of Post treatment Profiles.}

Tables 4 shows the degree of attractiveness according to the VAS scores, by treatment group, at the post treatment examination. No significance statistically was observed in both groups at 5\% level of confidence.

Table 4: Results of $\mathrm{t}$ - test evaluating the signed VAS changes treatment in evaluation of the Silhouettes at the Posttreatment examination for both groups:

\begin{tabular}{|l|l|l|l|l|l|l|l|l|l|}
\hline \multirow{2}{*}{ Group } & \multirow{2}{*}{$\mathrm{N}$} & \multicolumn{7}{|c|}{ 95\% Confidence Interval of the Difference } \\
\cline { 3 - 10 } & Mean & $\begin{array}{c}\text { Std. } \\
\text { Deviation }\end{array}$ & $\begin{array}{c}\text { Std. Error } \\
\text { Mean }\end{array}$ & Upper & Lower & df & $\mathrm{t}$ & Sig. (2-tailed) \\
\hline GP 1 & 10 & 298.00 & 94.610 & 29.918 & 365.680 & 230.320 & 9 & 9.960 & .000 \\
\hline GP 2 & 10 & 292.50 & 130.963 & 41.414 & 386.186 & 198.815 & 9 & 7.063 & .000 \\
\hline
\end{tabular}

Group 1 (TFBC)

Group 2 (Edgewise)

\section{DISCUSSION}

At the heart of this study is the question of whether the use of a TFBC in combination with Edgewise mechanics yields a more esthetic facial profile than Edgewise treatment alone. Because the integumental profile depends considerably on the underlying bony (skeletodental) support, it follows that the obvious way an orthodontist can improve the patient's soft-tissue profile is to improve the harmony of the underlying supporting structures. So too, it is relevant to the design of this study that the starting conditions of the two treatment modalities be as comparable as possible. The purpose of this section is to document that key cephalometric conditions were comparable at the start of treatment. 
In contrast, we first evaluated the TFBC sample and matched an Edgewise case to each based on what we deemed key characteristics of the skeletal malocclusion.

For each TFBC case, the pool of Edgewise - treated cases was reviewed to provide a close match for the four cephalometric variables. Operationally, we felt there was adequate precision if all the four variables "matched" within 1 or 2 degrees of the case accounting for the expected sex-specific age changes (Riolo et al. 1974) $^{14}$. Pointedly, we made no special effort to match for dental characteristics of the malocclusion, though all cases began treatment as Class II, division 1 malocclusions.

On the other hand, silhouettes have the advantages of subjectivity and simplification of facial aesthetics, discarding many extrinsic (hair style, make up) and intrinsic (skin complexion, emotional expression) factors that may influence the individual's concept of beauty. The use of lateral facial silhouettes may be of more interest to orthodontic raters than other studies who used a group of lay people $(\mathrm{n}=26)$ participated frontal facial silhouettes in study (Selin et.al., 2010) ${ }^{15}$.

We think that the ranking procedure by the modification, we did in this study, from 100-mm visual analogue scale VAS mm scale - into 100 $\%$ scale, made the rating procedure more simple and faster.

The results showed no significance statistically among the observers' perceptions of pretreatment and post treatment, and perceptions of post treatment profiles $(p<0.05)$. This considerable variation in selecting the most attractive profiles could be due to differences and the wide range of opinions among the observers. While in another research by (Marina et.al., 2010) ${ }^{16}$ the results showed agreement between the raters regardless of gender. The gender of the evaluators was not considered in this research because of the small number of the raters.

It should be taken into consideration that the results of this study are derived from only a small number of photographs and evaluators, which might limit the conclusions. 
Egyptian

Orthodontic Journal

\section{CONCLUSION}

There was no difference between the two groups in the perceived amounts of profile change with treatment. TFBC treatment in combination with Edgewise mechanics has measurable benefits. The ranking procedure using $100 \%$ visual analogue scale is a simple, rapid, and reliable method for the assessment of attractiveness.

\section{ACKNOWLEDGEMENT}

- To Nashwa M.E. Lecturer of Mathematics, Faculty of Science, Suez Canal University, for her help in the construction of statistical analysis of this study.

\section{REFERENCES}

1. Shaw WC. The influence of children's dentofacial appearance on their social attractiveness as judged by peers and lay persons. Am J Orthod 1981;79:399-415.

2. Shaw WC, Rees G, Dawe M, Charles CR. The influence of dentofacial apperarnce on the social attractiveness of young adults. Am J Orthod 1985;87:21-6.

3. Birkeland K, Boe OE, Wisth PJ. Relationship between occlusion and satisfaction with dental appearance in orthodontically treated and untreated groups. A longitudinal study. Eur J Orthod 2000; 22:509-18.

4. Shaw WC, Gabe MJ, Jones BM. The expectations of orthodontic patients in South Wales and St. Louis, Missouri. Br J Orthod 1979;6:203-5.

5. Spyropoulos MN, Halazonetis DJ. Significance of the soft tissue profile on facial esthetics. Am J Orthod Dentofacial Orthop 2001;119:464-71.

6. Vig KW, Weyant R, O’Brien K, Bennett E. Developing outcome measures in orthodontics that reflect patient and provider values. Semin Orthod1999;5:85-95.

7. Graber TM, Vanarsdall RL Jr, Vig KW. Orthodontics: current principles and techniques, 4th ed. St. Louis: Elsevier Inc; 2005.

8. Shelly AD, Southard TE, Southard KA, Casko JS, Jakobsen JR, Fridrich KL, et al. Evaluation of profile esthetic change with mandibular advancement surgery. Am J Orthod Dentofacial Orthop $2000 ; 117: 630-7$ 
9. Mergen JL, Southard KA, Dawson DV, Fogle LL, Casko JS, Southard TE. Treatment outcomes of growing Class II division 1 patients with varying degrees of anteroposterior and vertical dysplasias, Part 2. Profile silhouette evaluation. Am J Orthod Dentofacial Orthop 2004;125:457-62.

10. Howells DJ, Shaw WC. The validity and reliability of ratings of dental and facial attractiveness for epidemiologic use. Am J Orthod 1985;88:402-8.

11. Proffit WR, Phillips C, Douvartzidis N. A comparison of outcomes of orthodontic and surgical-orthodontic treatment of Class II malocclusion in adults. Am J Orthod Dentofacial Orthop 1992;101:556-65.

12. Bowman SJ, Johnston LE. The esthetic impact of extraction and nonextraction treatments on Caucasian patients. Angle Orthod 2000;70:3-10.

13. O’Neill K, Harkness M, Knight R. Ratings of profile attractiveness after functional appliance treatment. Am J Orthod Dentofacial Orthop 2000;118:371-6.

14. Riolo ML, Moyers RE, McNamara JA Jr, Hunter WS. An atlas of craniofacial growth: cephalometric standards from the University School Growth Study, the University of Michigan. Monograph 2, Craniofacial Growth Series. Ann Arbor: Center for Human Growth and Development, University of Michigan; 1974.

15. Selin Kale Varlık, Evren Demirbaş, and Metin Orhan. Influence of lower facial height changes on frontal facial attractiveness and perception of treatment need by lay people. The Angle Orthodontist: November 2010, Vol. 80, No. 6, pp. 1159-1164.

16. Marina Dórea de Almeida; Arthur Costa Rodrigues Farias; Marcos Alan Vieira Bittencour: Influence of mandibular sagittal position on facial esthetics. Dental Press J. Orthod. vol.15 no.2 Maringá Mar./Apr. 2010 